\title{
Defender a ciência é hoje um ato político decisivo
}

\section{Defending science today is a decisive political act}

\section{Defender la ciencia hoy es un acto político decisivo}

\author{
Natanael Vitor Sobral ${ }^{1, a}$ \\ natanael.sobral@ufpe.br | https://orcid.org/0000-0003-2410-494X \\ Leilah Santiago Bufrem ${ }^{2, b}$ \\ santiagobufrem@gmail.com | https://orcid.org/0000-0002-3620-0632
}

\footnotetext{
${ }^{1}$ Universidade Federal de Pernambuco, Departamento de Ciência da Informação. Recife, PE, Brasil.

2 Universidade Federal de Pernambuco, Programa de Pós-Graduação em Ciência da Informação. Recife, PE, Brasil.

a Doutorado em Ciência da Informação pela Universidade Federal da Bahia.

b Doutorado em Ciências da Comunicação pela Universidade de São Paulo.
}

Palavras-chave: Estudos métricos da informação; Comunicação científica; Informação científica em saúde; Indicadores científicos em saúde; Políticas científicas.

Keywords: Metric studies of information; Scientific communication; Scientific information about health; Scientific health indicators; Scientific policies.

Palabras clave: Estudios métricos de la información; Comunicación científica; Información científica sobre la salud; Indicadores científicos de la salud; Políticas científicas.

A Revista Eletrônica de Comunicação, Informação e Inovação em Saúde (Reciis) traz a este último número do ano uma relevante discussão com estudos métricos frente às interfaces da comunicação, informação e saúde. Entre os trabalhos publicados, estão também presentes textos que refletem sobre as desigualdades de gênero em torno da figura da mulher, a gestão de repositórios institucionais, os enlaces e desdobramentos diante da pandemia de covid-19 e as representações sobre o direito à Comunicação e Saúde.

Integrado a esta edição, o dossiê temático ‘Estudos métricos da informação científica em saúde’ refere-se a um campo acadêmico e profissional privilegiado neste momento histórico, quando disputas pelo status de cientificidade permeiam o cenário sociopolítico do Brasil e do mundo. A construção desse espaço científico vem convergindo para resultados teóricos e reflexões epistemológicas capazes de produzir transformações e aperfeiçoar os modos e formatos de produção e comunicação do conhecimento. Entretanto, embora esse processo de consolidação do espaço universitário, com aumento de cursos de graduação e pós-graduação fortalecendo-o como multiprofissional e interdisciplinar a partir da década de 2000, tenha contribuído para o surgimento de formatos e práticas de pesquisa, deparamo-nos, neste momento histórico de pandemia, 
com algumas questões: a instabilidade política e a urgência de encontrar formas de responder às demandas de saberes próprios e específicos requeridos pela situação de crise e as decorrentes necessidades sociais de saúde proporcionais às necessidades da população, especialmente devido à ordem econômica capitalista.

Abrangendo produções teóricas e práticas, o campo da saúde tende a ultrapassar as fronteiras dos domínios científicos, tanto na dimensão teórica, quanto no âmbito de práticas, passando a envolver problemas sociais e questões éticas, cujos objetos de discussões têm trânsito em campos do conhecimento diversos, com impacto positivo sobre as ações emergenciais.

Os estudos métricos da informação são fundamentais para o conhecimento de um domínio e, com este dossiê, evidenciam-se suas contribuições para a ciência na análise e avaliação dos saberes científicos produzidos, nas suas relações, determinações e na formulação de políticas públicas, a partir do reconhecimento, sistematização e crítica da produção científica. Esses estudos podem contribuir para a organização e reconhecimento de padrões e explicitar os relacionamentos entre elementos constituintes da produção científica, como autores, documentos, instituições, assim como formas, posicionamentos e dinâmicas presentes no ambiente acadêmico. Dentre as possibilidades analíticas observáveis na literatura, são perceptíveis as variáveis: autoria, assuntos, fontes, períodos, instituições, países, citações, acessos, compartilhamentos, curtidas, reações, entre outras, constituintes de uma infinidade de elementos constantes na realidade clássica e contemporânea dos estudos de produção científica.

Voltadas para a saúde, as pesquisas com base em estudos métricos unem-se aos esforços presentes no campo, colaborando para as iniciativas de prevenção e combate às doenças, fortalecendo as atividades de pesquisa e a cobertura universal de saúde. Essa cooperação se dá a partir de meios mais efetivos de distribuição de recursos, mapeamento de grupos especializados de pesquisadores para a resolução de problemas de saúde pública, seleção de canais para a disseminação da produção científica, e alinhamento das necessidades de pesquisa às demandas sociais em saúde. Além disso, esses estudos propiciam o desenvolvimento e a avaliação de estratégias para a interação entre cientistas e a sociedade nas plataformas digitais.

Com esses intuitos, o dossiê 'Estudos métricos da informação científica em saúde' cumpre o papel de proporcionar à coletividade um conjunto de publicações científicas revisadas por pares e selecionadas por uma política editorial orientada pelos estatutos científicos e pelo espírito crítico. Assim, movidos pelo dever de combater todas as formas de negacionismo, retrocesso e obscurantismo, reunimos múltiplos saberes que reafirmam o papel essencial dos estudos métricos diante de crises e catástrofes em que o protagonismo da ciência se faz necessário, somando-se às luzes que brilham sobre as trevas da desinformação e da ignorância, ao sistematizar e promover o incansável trabalho dos cientistas e das instituições. Apoiar estes princípios é fundamento decisivo para a preservação da civilização em oposição à barbárie anti-intelectual que busca preterir a ciência em prol de interesses escusos e retrógrados, compatíveis apenas com tempos medievais e autoritários.

O primeiro artigo do dossiê, escrito por Hebert Luan Pereira Campos dos Santos, Taise de Alcantara Almeida, Hildebrando Antunes de Carvalho Neto, Maria de Lourdes Lacerda Lemos, Josilene Silva Oliveira, Eliana Amorim de Souza e Nília Maria de Brito Lima Prado, realiza uma análise bibliométrica da produção científica brasileira sobre doença de Chagas, a partir das publicações indexadas na base de dados Web of Science. Segundo os autores, a bibliometria permitiu obter um panorama da produção acadêmica nacional, de modo a desvelar as lacunas ainda existentes na produção e a necessidade de fortalecimento de políticas direcionadas a editais de pesquisa no país. Além disso, o texto reforça a importância do combate às doenças negligenciadas, especialmente a doença de Chagas, considerada uma das patologias de mais larga distribuição no continente americano, com elevada prevalência e expressiva morbimortalidade (SANGENIS et al., 2016). 
O segundo artigo, dos autores Rene Faustino Gabriel Junior, Fernanda Bochi e Ana Maria Mielniczuk de Moura, analisa as aproximações da produção científica em ciências da saúde na área de ciência da informação no Brasil, com base nos artigos indexados na Base de Dados em Ciência da Informação (Brapci), no período de 1972 a 2020. Foram coletados 1.293 documentos, restando após a limpeza o total de 1.140 registros. Os autores observaram que 3,3\% dos documentos em Ciência da Informação indexados na mencionada base abordam alguma questão da área de saúde. A Reciis apresentou 43,2\% de todos os trabalhos recuperados, o que reforça o protagonismo do periódico nos estudos em comunicação, informação e inovação em saúde.

O terceiro texto, publicado também em inglês nesta edição, elaborado por Rosane Abdala Lins, Rosangela Cordeiro de Souza Assef Neto, Cícera Henrique da Silva e Maria Cristina Soares Guimarães, descreve a publicação brasileira em colaboração com outros países sobre o coronavírus ao longo dos anos, mostrando, especificamente, a produtividade durante as epidemias relacionadas ao vírus. Para isto, as autoras recuperaram 3.255 publicações, entre 1989 e 2020, das quais 1.310 se deram mediante colaboração científica internacional. Realizaram-se descrições em relação à nacionalidade, afiliação institucional, periódicos que publicaram os trabalhos e sua área temática. As publicações em coautoria sobre covid-19, envolveram 148 países, sendo que 104 deles são novos parceiros. Ao longo do período analisado, novas áreas de conhecimento foram incorporadas na discussão sobre o tema, traduzindo o caráter multidisciplinar das pesquisas ligadas às emergências em saúde.

O quarto estudo, produzido por Bruno Elias Penteado, Marcelo Fornazin, Leonardo Castro e Sandro Freire apresenta resultados de uma pesquisa bibliométrica sobre a evolução conceitual e tecnológica do campo da informática médica nas últimas décadas, enfatizando aspectos metodológicos. O trabalho realizou análise bibliométrica em metadados de 100 mil artigos indexados sob a categoria 'medical informatics' na base de dados Web of Science, entre os anos de 1960 e 2020. Foram realizadas análises longitudinais com utilização dos softwares Bibliometrix e CorText em três eixos: quantidade de publicações, países dos autores e palavras-chave. Conforme a hipótese metodológica que orientou o estudo, as mudanças terminológicas verificadas ao longo do tempo oferecem uma visão aproximada das mudanças conceituais e tecnológicas do campo de pesquisa informática médica. Os resultados apontam que este campo de investigação apresentou crescimento consistente ao longo das últimas seis décadas, expandindo-se para diferentes países.

O quinto artigo, apresentado por Juliana Lazzarotto Freitas, Maria Cláudia Cabrini Grácio e Leilah Santiago Bufrem, analisa o interdomínio entre os estudos métricos de informação e medicina, reconhecendo esse espaço de produção científica a partir de indicadores de produção e de colaboração relacionados a autores, periódicos e instituições. Caracteriza o interdomínio em um corpus de 132 artigos da autoria de 28 pesquisadores, em um período de 28 anos, apresentando os autores, periódicos e instituições de maior destaque, bem como as relações de coautoria e de cocitação entre autores e periódicos. Define agrupamentos de autores e de periódicos, identificando os mais representativos do interdomínio analisado. Qualifica os artigos conforme os seus enfoques, segundo os três grupos-alvo da bibliometria, presentes em Glänzel (2003), e identifica as suas temáticas de pesquisa. Conclui que os autores mais representativos do interdomínio apresentam estudos com enfoques nos três grupos-alvo e que o periódico Scientometrics é o que estabelece a articulação das pesquisas constituintes do interdomínio de forma mais consistente.

Relacionando-se com o tema abordado neste dossiê, tem-se a esclarecedora e necessária entrevista realizada com o médico, professor titular e pesquisador Airton Tetelbom Stein, enfatizando que epidemias e pandemias, como a da covid-19, revelam o impacto das mudanças climáticas na saúde da população. Ressalta que um dos pilares da Atenção Primária à Saúde (APS) é o entendimento sobre as causas do surgimento das doenças no âmbito populacional. Neste sentido, nas dinâmicas sociais, sobretudo as midiáticas acerca da covid-19, o pesquisador esclarece que as decisões sobre o tratamento precoce e sobre tomar ou não a vacina dizem respeito à valorização de pressupostos baseados em informações não sistematizadas em detrimento 
de metodologias robustas, referem-se às decisões individuais que impactam a saúde da população. "As pessoas que têm se negado a realizar a vacinação precisam entender que isso não é apenas uma liberdade individual" (p. 1039).

Ademais, tem-se a excelente nota de conjuntura, em espanhol, escrita pela professora e pesquisadora da Universidade Federal do Rio Grande do Norte, Nancy Sanchéz-Tarragó, e pela pesquisadora do Centro Nacional de Información de Ciencias Médicas, de Cuba, Grisel Zacca González, que apresenta uma breve análise da emergência de saúde pública devido à covid-19 e algumas das questões mais relevantes relacionadas à informação e comunicação em saúde. Desta forma, as autoras contextualizam a utilidade da aplicação de estudos métricos de informação em realidades multidimensionais, contribuindo para iluminar fenômenos complexos como os associados à emergência da covid-19, permitindo um melhor entendimento de seus aspectos científicos, sociais e políticos, e respostas mais precisas por parte de gestores e acadêmicos.

Diante do alto interesse da comunidade científica e da alta qualidade dos artigos submetidos, o presente dossiê será publicado em duas partes. A segunda, a ser lançada nos primeiros meses de 2022 contará com pesquisas relacionadas à produção científica sobre covid-19; coautoria institucional na produção científica brasileira sobre hanseníase; busca de informações sobre covid-19 na web, numa perspectiva cibermétrica; redes semânticas sobre covid-19 na Web of Science; e produção científica brasileira em odontologia. Este conjunto expressa a pluralidade dos estudos métricos da informação em saúde e demonstra o comprometimento dos pesquisadores e das instituições científicas brasileiras com a produção de conhecimento, mesmo diante das adversidades existentes.

Para superá-las, seriam necessárias intervenções de natureza crítica, teóricas e práticas. As teóricas já permeiam a literatura, como ilustra bem este dossiê, entre tantas outras produções das mais diversas especialidades e naturezas, organizadas para que se possa compreender, nomear e tornar visíveis as políticas e práticas autoritárias suscetíveis aos parâmetros do capitalismo. Entretanto, qualquer estudo sobre o tema torna-se apenas uma possibilidade de exploração em terreno incerto e duvidoso, resultando, portanto, em maior fragilidade nas intervenções de natureza crítica e prática, especialmente no Brasil, protagonista do mapa da fome, onde não são atendidas as necessidades da população, havendo um projeto em curso de precarização sistemática do serviço público, comprometendo, especialmente, a educação, a ciência e a saúde, cuja defesa não pode ser descuidada ou adiada.

No atual contexto, marcado por uma política intimidatória do conhecimento científico e do pensamento crítico, dos movimentos sociais e das ações coletivas, é crucial o fortalecimento das estruturas públicas de informação, educação e saúde. Vale retomar a exigência marxiana para a entrada na ciência (MARX, 2008), ilustrada divinamente por Dante, referindo-se à entrada no Inferno: Qui si convien lasciare ogni sospetto; ogni viltà convien che qui sia morta (Deixe-se aqui tudo o que é suspeito; mate-se aqui toda vileza).

\section{REFERÊNCIAS}

GLÄNZEL, Wolfgang. Bibliometrics as a research field: a course on theory and application of bibliometric indicators. Hacettepe: [s. n.], 2003. 115 p. Disponível em: https://yunus.hacettepe.edu.tr/ tonta/courses/ spring2011/bby704/Bib Module KUL.pdf. Acesso em: 1 nov. 2021.

MARX, Karl. Prefácio à Contribuição à crítica da Economia Política. In: MARX, Karl. Contribuição à crítica da Economia Política. Tradução: Florestan Fernandes. 2. ed. São Paulo: Expressão Popular, 2008. p. 45-50.

SANGENIS, Luiz Henrique Conde et al. Transmissão da doença de Chagas por consumo de carne de caça: revisão sistemática. Revista Brasileira de Epidemiologia, São Paulo, v. 19, n. 4, p. 803-811, 2016. Disponível em: https://www.scielo.br/j/rbepid/a/C5Z4GNTtYxxtWfRkwRrvqRM/abstract/?lang=pt. Acesso em: 1 nov. 2021. 